\title{
Skeletal muscle targeting in vivo electroporation-mediated HGF gene therapy of bleomycin-induced pulmonary fibrosis in mice
}

\author{
Yukio Umeda ${ }^{1, *}$, Tsutomu Marui ${ }^{1, *}$, Yukihiro Matsuno ${ }^{1}$, Koyo Shirahashi ${ }^{1}$, Hisashi Iwata ${ }^{1}$, \\ Hisato Takagi ${ }^{1}$, Kunio Matsumoto ${ }^{2}$, Toshikazu Nakamura ${ }^{2}$, Atsushi Kosugi ${ }^{3}$, Yoshio Mori ${ }^{1}$ \\ and Hirofumi Takemura ${ }^{1}$ \\ ${ }^{1}$ Advanced Surgery, Department of Organ Pathobiology, Gifu University School of Medicine, Gifu, Japan; \\ ${ }^{2}$ Molecular Regenerative Medicine, Course of Advanced Medicine, Osaka University Graduate School of \\ Medicine, Suita, Osaka, Japan and ${ }^{3}$ School of Allied Health Sciences, Faculty of Medicine, Osaka University, \\ Suita, Osaka, Japan
}

\begin{abstract}
Lung fibrosis is a common feature of interstitial lung diseases, and apoptosis and fibrinogenesis play critical roles in its formation and progression. Hepatocyte growth factor (HGF) is one of the ideal therapeutic agents for prevention of lung fibrosis because of its antiapoptotic and fibrinolytic effects. The aim of this study is to establish nonviral HGF gene therapy of bleomycin-induced lung fibrosis avoiding the viral vector-related side effects. C57BL/6 mice were injected with $3.0 \mathrm{mg} / \mathrm{kg}$ body weight of bleomycin intratracheally. Following bleomycin injection, $50 \mu \mathrm{l}$ of pUC-HGF $(1 \mathrm{mg} / \mathrm{ml})$ was injected into each of the quadriceps muscle. Immediately after plasmid injection, in vivo electroporation was performed with pulse generator. Skeletal muscle-targeting electroporation induced transgene expression on day 1 and persisted for 4 weeks, and human HGF was also detected in the lung. In mice transferred with HGF, pathological score $(1.0 \pm 0.3$ vs $3.2 \pm 0.6)$, TUNEL-positive cell index (4.5 \pm 1.1 vs $14.2 \pm 3.1)$, and hydroxyproline content $(9.0 \pm 1.3$ vs $14.4 \pm 5.1 \mu \mathrm{mol} / \mathrm{g})$ were significantly reduced compared with the control. Furthermore, survival rate of HGF mice was significantly improved compared with the control. Our data indicate that HGF gene therapy with a single skeletal muscle-targeting electroporation has a therapeutic potential for bleomycin-induced lung fibrosis and this strategy can be applied as a practical gene therapy protocol for various organs.
\end{abstract}

Laboratory Investigation (2004) 84, 836-844, advance online publication, 3 May 2004; doi:10.1038/labinvest.3700098

Keywords: lung fibrosis; hepatocyte growth factor (HGF); gene therapy; in vivo electroporation

Pulmonary fibrosis is a common feature of interstitial pulmonary diseases. These disorders are progressive and refractory to current therapy and the limited fundamental therapeutic options are available to date. ${ }^{1}$ A number of animal models and therapeutic agents were developed to explore the possibility of a new fundamental strategy against pulmonary fibrosis. Bleomycin-induced pneumopathy is a well-established model of pulmonary fibrosis, and the acute toxicity of bleomycin is characterized as the DNA damage of pulmonary

Correspondence: Dr Y Umeda, MD, PhD, Advanced Surgery, Department of Organ Pathobiology, Gifu University, 40 Tsukasamachi, Gifu 5008705, Japan.

E-mail: umeda@cc.gifu-u.ac.jp

${ }^{*} \mathrm{YU}$ and TM equally contributed to this paper.

Received 21 October 2003; revised 15 February 2004; accepted 17 February 2004; published online 3 May 2004 tissue, which results in apoptosis. ${ }^{2}$ Following the induction of apoptosis, immunological mechanisms including the further induction of apoptosis are also involved in the progression of the bleomycininduced pulmonary fibrosis. ${ }^{3}$

On the other hand, hepatocyte growth factor (HGF) is mitogenic and antiapoptotic factor for alveolar and bronchial epithelial cells. It also stimulates the migration and morphogenesis of those cells as reported in the previous in vitro studies. $^{4,5}$ Yaekashiwa et $a l^{6}$ demonstrated that continuous systemic injection of recombinant HGF suppressed pulmonary fibrosis induced by bleomycin in the mice model. HGF had significant effect when it was administered simultaneously or subsequently to bleomycin treatment. ${ }^{6}$ Although these studies suggested the therapeutic potential of recombinant HGF for bleomycin-induced pulmonary fibrosis, the feasibility of HGF gene transfer has not 
been fully explored. When delivered to the lung in vivo, in addition to the innate immune response or nonspecific inflammation, cellular and humoral immune responses are especially critical issues in the use of viral vectors. Furthermore, pathologically abnormal lungs present disease-specific barriers that can limit gene transfer. ${ }^{7}$

In current clinical gene therapy, viral vectormediated gene transfer is the most popular gene delivery system. On the other hand, serious concerns regarding the possibility of insertional mutagenesis and induction of the host immune response limit their clinical desirability. When a retroviral vector-mediated gene transfer was used, an antihypertensive gene was transmitted to the offspring and integrated into its genome. ${ }^{8}$ In liver-directed clinical gene therapy, adenoviral vector-mediated gene transfer induced fulminant hepatic failure that lead to mortality. ${ }^{9}$ Adenoassociate virus (AAV) vector have been found to be efficient for transducing nonproliferating cells and is considered to be nonpathogenic. Gene delivery by AAV vector also appears to be the least immunogenic of the viral vector systems. However, a major problem associated with the use of AAV vector has been the difficulty in producing large quantities of high-titer stock.

Previously, to avoid these viral-vector related side effects and complexity of viral gene transfer, we developed nonviral gene gun-mediated gene transfer ${ }^{10-12}$ and in vivo electroporation. ${ }^{13}$ However, these nonviral gene transfer methods also induced infiltration of inflammatory cells and mechanical damage in targeted organs. Clinically, these nonviral gene transfer-related side effects in diseased organs are also critical.

We hypothesized that these nonviral gene transfer-related side effects would be avoided with the use of nondiseased-organ-targeting gene transfer. Especially in lung disease, as a result of skeletal muscle targeting gene transfer, secreted transgene product would reach the lung through the bloodstream with a certain concentration. Therefore, we investigated the possibility of the in vivo electroporation-mediated HGF gene transfer targeting skeletal muscle for bleomycin-induced pulmonary fibrosis in current study.

\section{Materials and methods}

\section{Construction of Plasmid DNA}

Human HGF cDNA (2.2 kb) was inserted between the EcoRI and NotI sites of the pUC-SR alpha expression vector plasmid. ${ }^{14}$ In this plasmid, transcription of HGF cDNA was under the control of the SR alpha promoter. pCAGGS-EGFP was generated as a control vector using the modified pCAGGS expression vector. ${ }^{15}$

\section{Animal Model of Pulmonary Fibrosis}

Male pathogen-free C57BL/6 mice, 8 weeks old, were obtained from Japan SLC (Shizuoka, Japan). After measurement of their body weight, the animals were anesthetized with intraperitoneal injection of pentobarbital sodium (Dainippon Pharmaceutical, Osaka, Japan), and the trachea was exposed following a cervical incision. Bleomycin $(3.0 \mathrm{mg} / \mathrm{kg}$ of body weight, Nippon Kayaku, Tokyo, Japan) was dissolved in $50 \mu \mathrm{l}$ of sterile saline and then injected intratracheally with a 30-gauge needle.

\section{In Vivo Electroporation-mediated Gene Transfer}

Following bleomycin treatment, the bilateral quadriceps muscles were exposed by bilateral longitudinal incisions of the thigh. A volume of $50 \mu \mathrm{l}$ of pUC-HGF $(1 \mathrm{mg} / \mathrm{ml})$ was injected into each of the quadriceps muscle with 30-gauge needle. Immediately after intramuscular injection of pUC-HGF, the muscle was held by an electrode (Figure 1a) and in vivo electroporation was performed with pulse generator (Square Electroporator CUY 21; NEPA GENE, Chiba, Japan). The voltage, pulse length, and number of pulses of electroporation were $40 \mathrm{~V}$, $50 \mathrm{~ms}$, and 18 times, respectively. A total of 49 mice were transferred with pUC-HGF, and another 49 mice were transferred with pCAGGS-EGFP as the control. In all, 25 mice of each treatment group were served for survival analysis until 28 days after bleomycin injection and in vivo electroporation. Six of residual 24 mice of each group were killed on $1,3,5$, and 7 days after bleomycin injection and in vivo electroporation. Then, gene expression of HGF or green fluorescent protein (GFP), collagen content of the lung, and histological findings including the apoptosis were evaluated.

\section{Detection of GFP and Human HGF Expression}

The right quadriceps muscle and the left lobe of the lung were excised then GFP expression was detected with fluorescent stereomicroscopy. The left quadriceps muscle and the right upper lobe of the lung were excised and homogenized on ice after dilution with an adequate volume of human HGF extraction buffer (Institute of Immunology, Tokyo, Japan). After centrifugation, the supernatant was collected and stored at $-80^{\circ} \mathrm{C}$ until assay. The concentration of human HGF was determined by means of enzyme-linked immunosorbent assay (ELISA) using anti-human HGF monoclonal antibody (Institute of Immunology, Tokyo, Japan). The antibody used in this study reacts specifically with human HGF and has little crossreactivity with mouse endogenous HGF. 
a

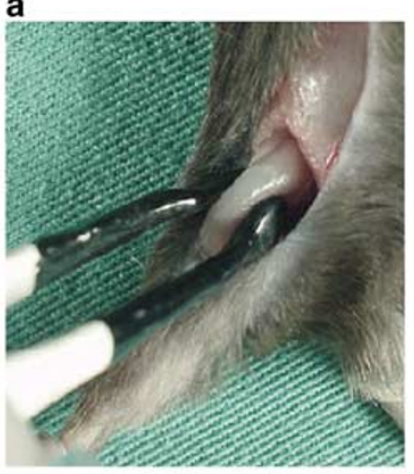

f

\begin{tabular}{l|cccccc} 
day & 1 & 3 & 5 & 7 & 14 & 28 \\
\hline GFP & $6 / 6$ & $6 / 6$ & $6 / 6$ & $6 / 6$ & $6 / 6^{*}$ & $5 / 6^{*}$ \\
HGF & $0 / 6$ & $0 / 6$ & $0 / 6$ & $0 / 6$ & $0 / 6$ & $0 / 6$
\end{tabular}

g

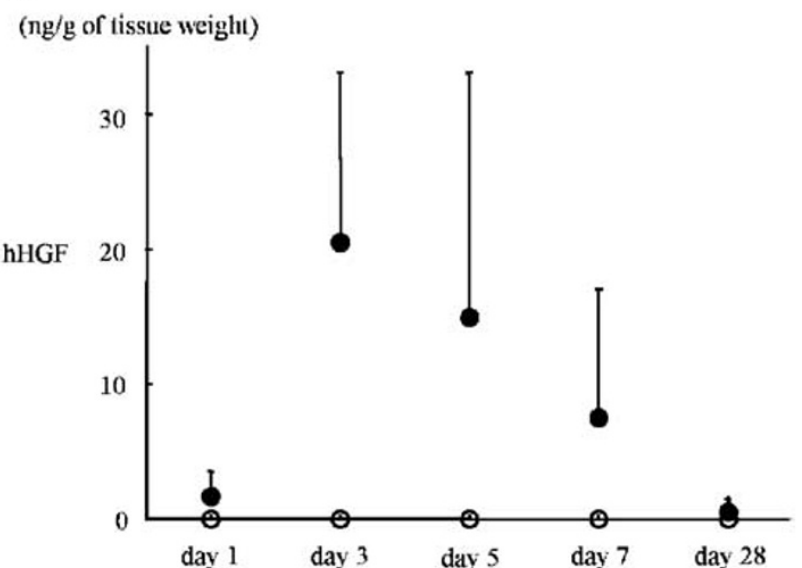

b

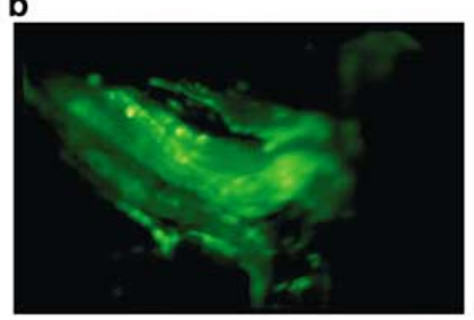

C

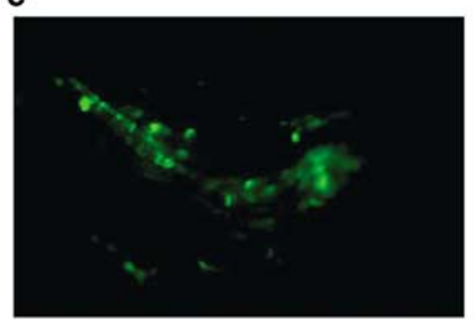

d
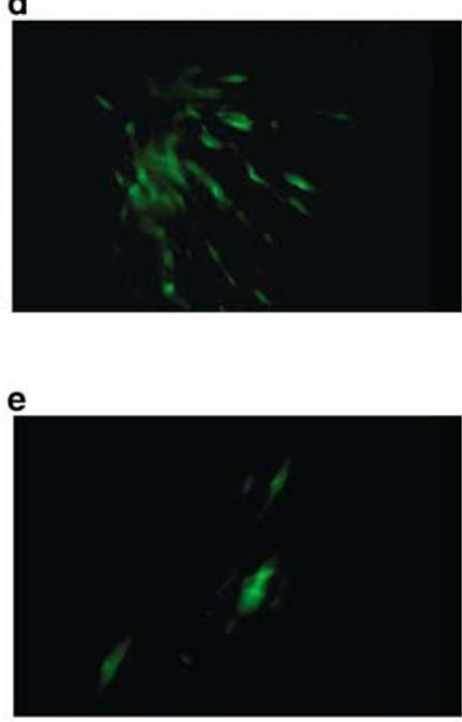

h

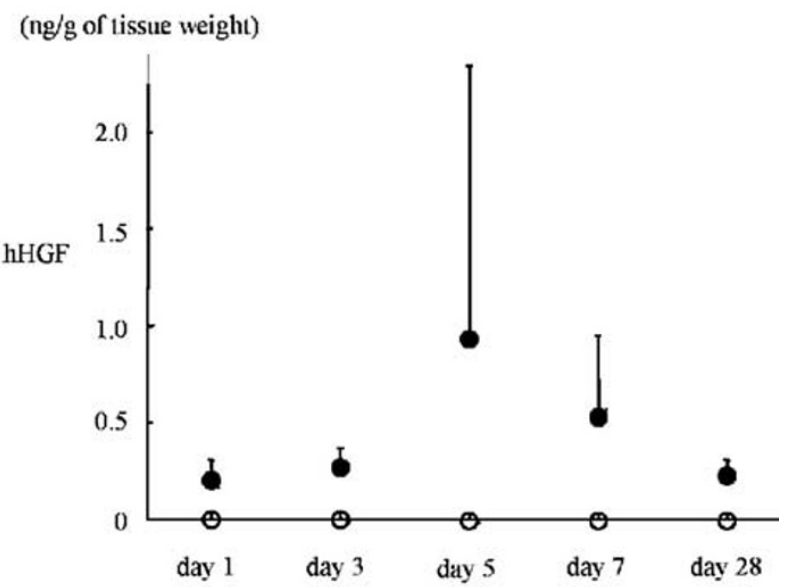

Figure 1 (a) Procedure of the skeletal muscle-targeting in vivo electroporation following intramuscular injection of plasmid DNA. (b-e) Expression of GFP in the quadriceps muscle at day 1 (b), 5 (c), 7 (d), and $28(\mathbf{e})$. Panel $\mathbf{f}$ represents the number of GFP positive mice. Asterisk ( ${ }^{*}$ ) indicates the data from bleomycin-untreated mice. (g and $\mathbf{h}$ ) Concentration of human HGF in the unilateral quadriceps muscle (g) or lung (h) at days 1, 3, 5, 7, 14, and 28; ( $(\bullet)$ human HGF level of mice transferred with pUC-HGF; (O) human HGF level of mice transferred with pCAGGS-EGFP. Each plot represents the mean value from six mice.

\section{Histological Analysis of In Vivo Electroporation- induced Tissue Damage}

To evaluate the tissue damage related to the in vivo electroporation, the right quadriceps muscle was fixed with $10 \%$ formaldehyde after the fluorescent stereomicroscopy for GFP expression analysis. The tissue was embedded in paraffin, and $4 \mu \mathrm{m}$ section of the quadriceps muscle was stained with hematoxylin-eosin.

\section{Histological Analysis for Bleomycin-induced Pulmonary Fibrosis}

The left lobe of the lung was obtained after the fluorescent stereomicroscopy for GFP expression analysis. After perfusion of the lung sample with phosphate-buffered saline solution (PBS), lung tissue was fixed by instilling $10 \%$ formaldehyde and embedded in paraffin. A $4 \mu \mathrm{m}$ section of the lung was used for Masson's trichrome staining. The section was reviewed under CCD microscopy (CCD; DP-70 (Olympus, Tokyo, Japan), microscope; Optiphot-2 (Nikon, Tokyo, Japan), objective lens; $\times 20$, adapter lens; $\times 0.45$, display size; $\left.21^{\prime \prime}\right)$. The extent of pulmonary fibrosis was evaluated according to the scoring system of Ashcroft et al. ${ }^{16} \mathrm{~A}$ score ranging from 0 (normal lung) to 8 (total fibrosis) was assigned for each of the five microscopic fields. The mean score of all fields was taken as the fibrosis score of lung section. 


\section{Evaluation of Lung Collagen Content by Hydroxyproline Assay}

The right lower lobe of the lung was excised and its hydroxyproline was measured. Briefly, after acid hydrolysis of the lung with $6 \mathrm{~N} \mathrm{HCl}$ at $110^{\circ} \mathrm{C}$ for $14 \mathrm{~h}$ in a sealed glass tube, hydroxyproline content was determined using high-performance liquid chromatography.

\section{Quantification of Apoptosis in Lung Tissue by Terminal Deoxynucleotidyltransferase dUTP Nick End Labeling}

Terminal deoxynucleotidyltransferase dUTP nick end labeling (TUNEL) in the left lobe of the lung was performed with an in situ apoptosis detection kit (Takara, Shiga, Japan) according to the manufacturer's protocol. The number of TUNEL-positive signals was counted in five fields under CCD microscopy. Apoptotic cell index was presented as the number of TUNEL-positive cells per 100 total cells.

\section{Statistical Analysis}

Data are expressed as mean \pm s.d. The statistically significant difference between treatments was assessed using a one-way analysis of variance followed by a parametric Student's $t$-test. Survival rates were estimated from survival curves based on the Kaplan-Meier method and compared with the Mantel-Cox log rank test. A $P$-value of less than 0.05 was considered significant.

\section{Results}

\section{In Vivo Electroporation-mediated GFP Gene Expression}

To confirm the efficacy of gene transfer by skeletal muscle-targeting in vivo electroporation, we detected GFP expression under fluorescent stereomicroscopy. The expression of GFP was exclusively detected along the muscle fiber of enhanced GFP (EGFP)transferred quadriceps muscle on the day after electroporation and persisted for 4 weeks (Figure 1b-f). Although GFP expression at day 28 was observed in five of six mice transferred with EGFP, the intensity of GFP in the quadriceps muscle at day 28 was slightly reduced compared with that measured in the early days. GFP expression was not detected in the HGF-transferred mice nor the other organs including the lungs of EGFP-transferred mice.

\section{In Vivo Electroporation-mediated HGF Gene Expression}

The expression of human HGF was detected in the quadriceps muscle of HGF-transferred mice from the day after in vivo electroporation to day 28 using human HGF-specific ELISA (Figure 1g). Concentration of human HGF in the unilateral quadriceps muscle was peaked at day $3(20.37 \pm$ $12.69 \mathrm{ng} / \mathrm{g}$ of tissue weight) and gradually decreased until day $28(0.49 \pm 1.01 \mathrm{ng} / \mathrm{g}$ of tissue weight). Although human HGF in the lung was also detected in the HGF-transferred mice and peaked at day 5 $(0.93 \pm 1.41 \mathrm{ng} / \mathrm{g}$ of tissue weight), its concentration
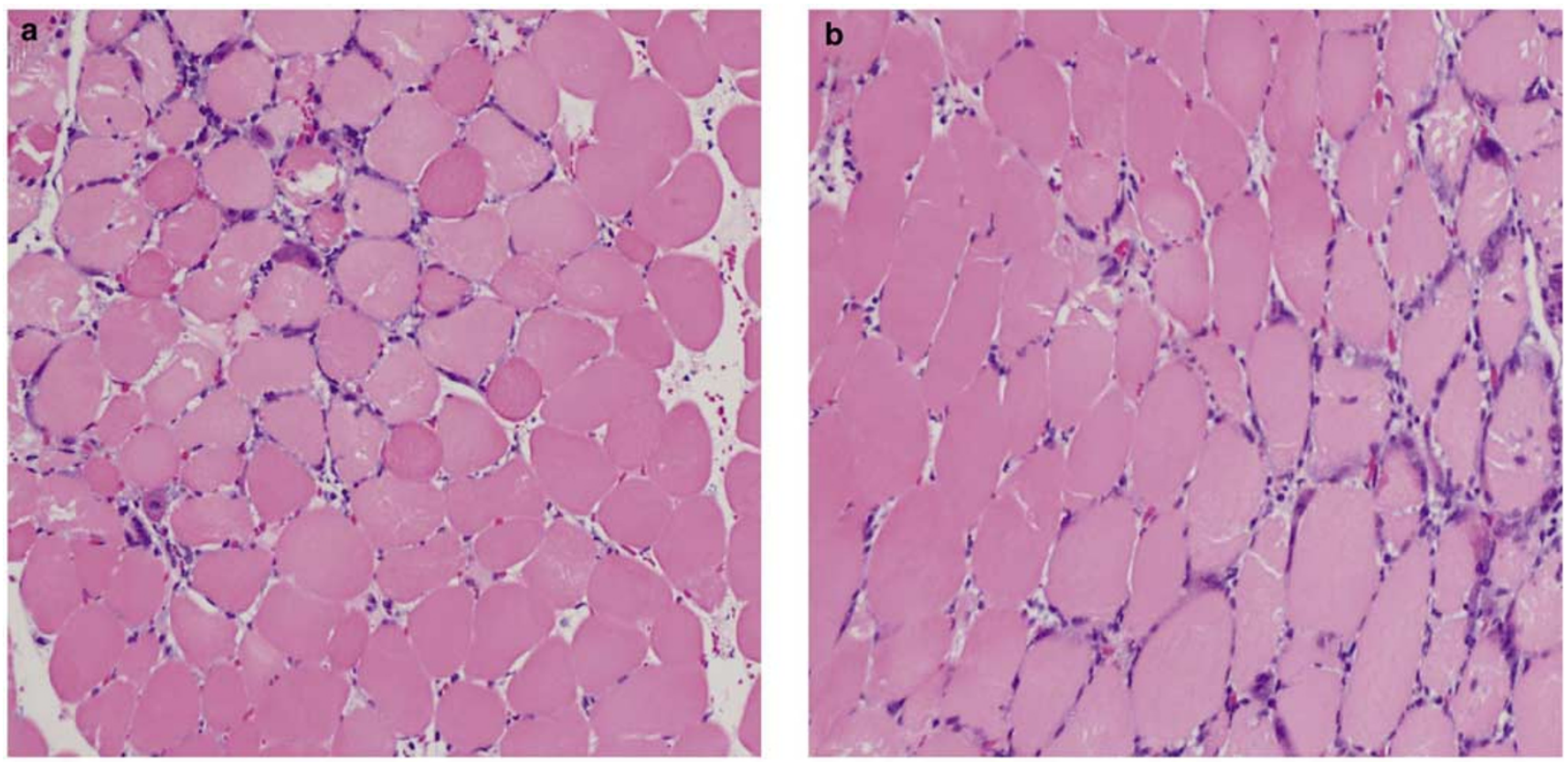

Figure 2 Histological damage of the quadriceps muscle induced by in vivo electroporation in GFP (a) or HGF (b)-transferred mice (hematoxylin-eosin staining). 
840
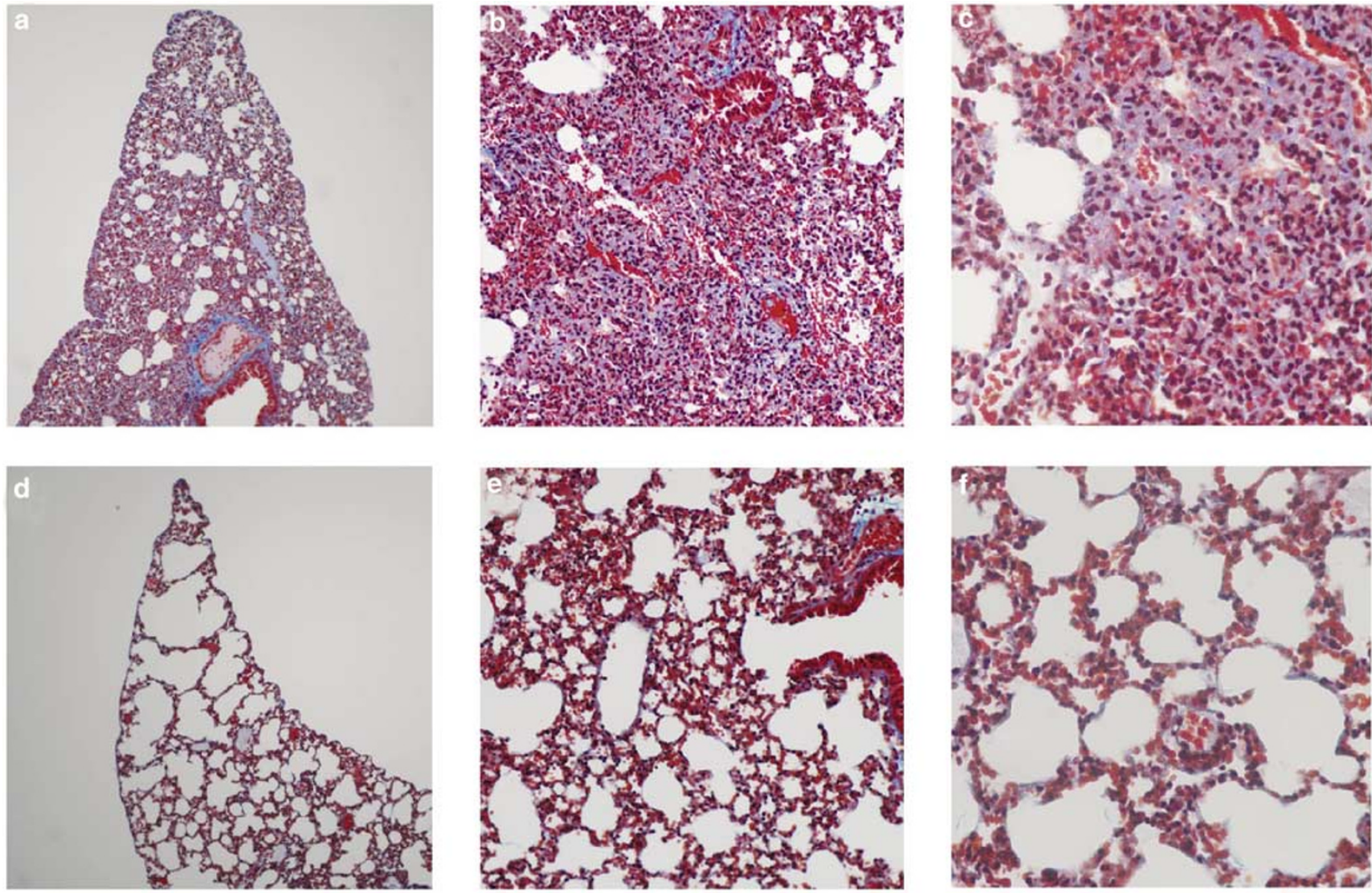

Figure 3 (a-f) Lung sections of mice treated with bleomycin (Masson trichrome staining). (a-c) Lung sections of mice transferred with pCAGGS-EGFP at day 7. (d-f) Lung sections of mice transferred with pUC-HGF at day 7.

was significantly lower than that in the quadriceps muscle (Figure 1h). Throughout this experiment, human HGF was not detected in the EGFP-transferred mice (Figure 1g, h).

\section{Effect of In Vivo Electroporation on the Skeletal Muscle}

Histologically, skeletal muscle-targeting in vivo electroporation induced minimal damage of the skeletal muscle fiber and mild degree of influx of inflammatory cells (Figure 2a, b). However, no dysfunction of the lower limb was observed in either group.

\section{Effect of HGF Gene Transfer on Bleomycin-induced Pulmonary Fibrosis}

Histologic finding in control mice showed increased cellularity and severe fibrotic changes. However, those changes were minimum in the mice injected with HGF. The fibrotic change of the lungs was assessed by the Ashcroft's numerical score at day 7 . The scores in the bleomycin-injected mice transferred with GFP (Figure 3a-c) and HGF (Figure 3d-f) were $3.2 \pm 0.6$ and $1.0 \pm 0.3$, respectively (Figure $4 \mathrm{a}$, $P<0.01)$. a

b

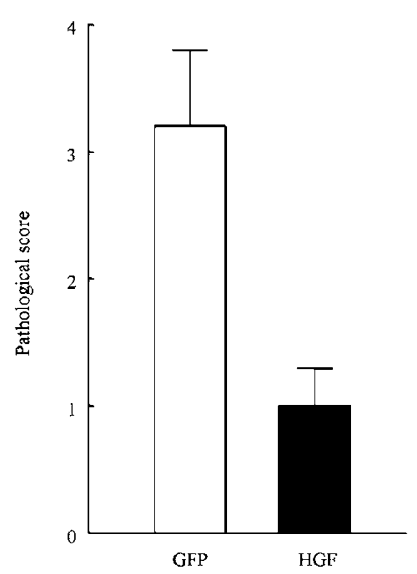

( $\mu \mathrm{mol} / \mathrm{g}$ of tissue weight)

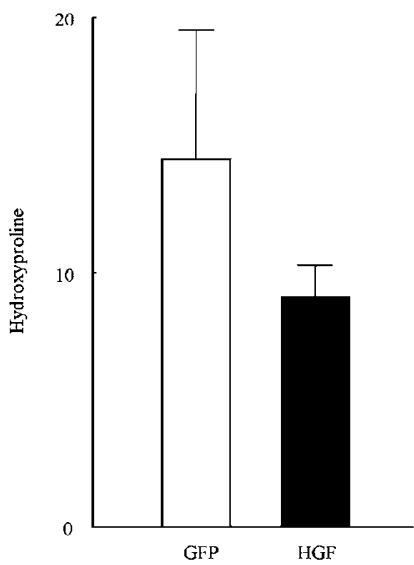

Figure 4 (a) Assessment of lung fibrosis using the Ashcroft's criteria for grading lung fibrosis at day 7. (b) Assessment of lung collagen content using hydroxyproline assay at day 7 .

\section{Effect of HGF Gene Transfer on Hydroxyproline Content of Bleomycin-injected Lung}

Collagen content of the bleomycin-injected lung was assessed by the hydroxyproline assay. There was a 

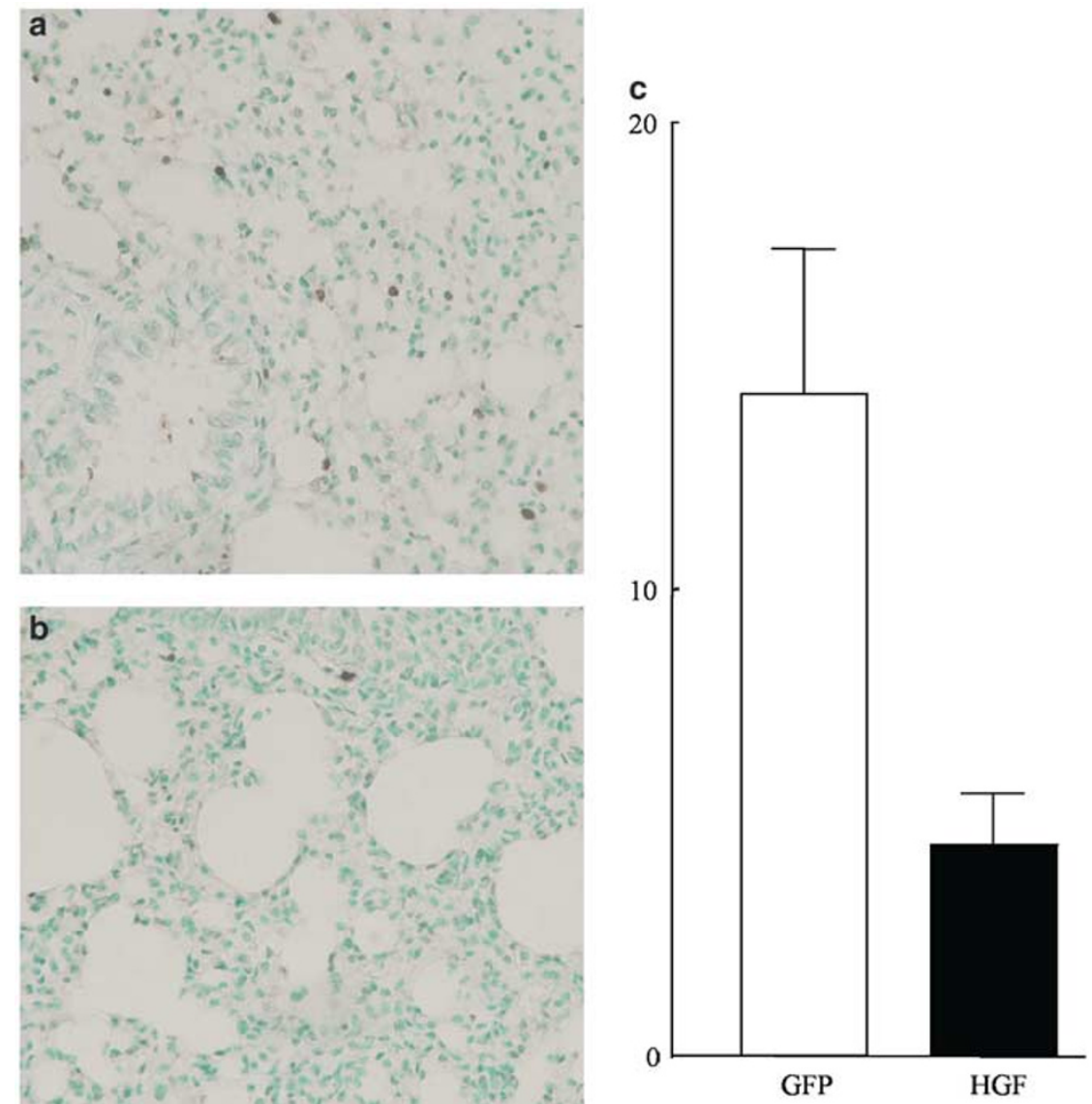

Figure 5 (a and b) Lung sections of mice treated with bleomycin (TUNEL staining). (a) Lung sections of mice transferred with pCAGGSEGFP at day 5. (b) Lung sections of mice transferred with pUC-HGF at day 5. (c) Apoptotic cell index at day 5 was presented as the number of TUNEL-positive cells per 100 total cells.

significant decrease in lung hydroxyproline content in mice transferred with HGF $(9.0 \pm 1.3 \mu \mathrm{mol} / \mathrm{g}$ of tissue weight) compared with that in control mice $(14.4 \pm 5.1 \mu \mathrm{mol} / \mathrm{g}$ of tissue weight) at day 7 (Figure 4b, $P<0.05$ ).

\section{Effect of HGF Gene Transfer on Apoptosis in Bleomycin-injected Lung}

Apoptotic cell index in bleomycin-injected lungs was significantly reduced in mice transferred with HGF $(4.5 \pm 1.1)$ compared with GFP $(14.2 \pm 3.1)$ at day 5 (Figure 5a-c, $P<0.0001$ ).

\section{Effect of HGF Gene Transfer on Survival after Bleomycin Injection}

In total, 25 mice transferred with HGF after bleomycin treatment and 25 mice with GFP were served for survival analysis. Within 28 days, three of the mice with HGF and 20 with GFP had died. The Mantel-Cox log rank test showed that the survival

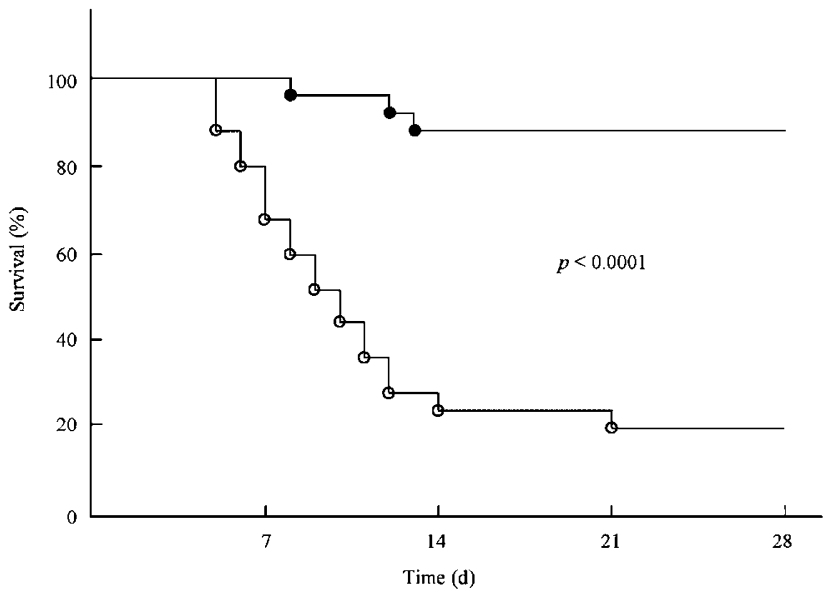

Figure 6 Survival of the bleomycin-treated mice: (0) mice transferred with pUC-HGF and $(\bigcirc)$ mice transferred with pCAGGSEGFP. Survival curves were presented as a Kaplan-Meier plot. Mantel-Cox log rank test was used for comparison of survival curves.

rate of mice with HGF was significantly improved compared with that of control mice (Figure 6, $P<0.0001)$. 


\section{Discussion}

$\mathrm{HGF}^{17}$ is a multipotent growth factor that acts as mitogen, ${ }^{14}$ motogen, ${ }^{18}$ and morphogen ${ }^{19}$ on various epithelial cells. Furthermore, HGF also has an antiapoptotic effect on these cells ${ }^{20}$ and fibrinolytic activity via upregulating urokinase-type plasminogen activator expression. ${ }^{21,22}$ Therefore, HGF has been obtained as a protective agent for a variety of organ disorders, such as liver cirrhosis, ${ }^{23}$ intestinal ischemia, ${ }^{24}$ myocardial ischemia, ${ }^{25}$ and acute renal failure. $^{26}$

On the other hand, pulmonary fibrosis is the most common feature of interstitial pulmonary diseases and this disorder is progressive and refractory to current therapy. Limited fundamental therapeutic options are available to date. ${ }^{1} \mathrm{~A}$ number of animal models and therapeutic agents were developed to explore the possibility of a new fundamental strategy against pulmonary fibrosis. Bleomycininduced pneumopathy is a well-established model of pulmonary fibrosis. Acute toxicity of bleomycin is characterized as the DNA damage of pulmonary tissue, which results in apoptosis. ${ }^{2}$ As found in bleomycin-treated mice, ${ }^{27}$ Fas expression in bronchiolar and alveolar epithelial cells and upregulation of Fas ligand (FasL) expression are also found in clinical idiopathic pulmonary fibrosis patients. ${ }^{28}$ Furthermore, an activation of apoptotic pathway was found in acute respiratory distress syndrome (ARDS), ${ }^{29}$ or other experimental models, such as lipopolysaccharide, ${ }^{30,31}$ hyperoxia, ${ }^{32,33}$ asbestos, ${ }^{34}$ and ischemia/reperfusion-induced lung injury, ${ }^{35}$ Thus, apoptosis is a common feature found in both clinical and experimental models of lung injury. Following the acute toxicity of bleomycin, immunological mechanisms by $\mathrm{T}$ cells, its cytokines and natural killer cells also concern the progression of lung fibrosis. ${ }^{3,36,37}$ In concurrence with these processes, extravasation of plasma through hyperpermeable vasculatures and injured alveolar walls occurs and tissue factor triggers the coagulation cascade, leading to fibrin deposition. ${ }^{38}$ Fibrin matrix serves as a scaffold in which fibroblasts migrate and induce collagen deposition.

From the therapeutic point of view, suppressions of apoptosis and fibrinogenesis are critical in prevention of the onset and progression of lung fibrosis. As HGF has both antiapoptotic and fibrinolytic potential as described above, HGF is one of the ideal therapeutic agents for lung fibrosis. Yaekashiwa et $a l^{6}$ reported that systemic injection of recombinant HGF suppressed pulmonary fibrosis induced by bleomycin in a mice model. Although their study suggested the therapeutic potential of HGF for bleomycin-induced pulmonary fibrosis, relatively high dose and continuous administration of recombinant HGF were required to induce those therapeutic effects. Since HGF has a short half-life ( $T_{1 / 2} 3-5 \mathrm{~min}$ ), HGF gene therapy would be desirable from a clinical point of view.
In current clinical gene therapy, viral vectormediated gene transfer is the most popular gene delivery system. However, in the use of adenoviral vector or retroviral vector, serious concerns regarding the possibility of insertional mutagenesis and induction of the host immune response limit their clinical desirability. With regard to newly developed AAV vector, it has been found to be efficient for transducing nonproliferating cells and is considered to be nonpathogenic. Gene delivery by AAV vector also appears to be less immunogenic. However, a major problem associated with the use of AAV vector has been the difficulty in producing large quantities of high-titer stock. Therefore, we previously explored the in vivo nonviral gene transfer systems, such as particle delivery using gene gun ${ }^{10-12}$ and electroporation using pulse generator, ${ }^{13}$ to avoid these viral vector related problems. ${ }^{8,9}$ In the gene gun-mediated gene transfer to the mice liver, gene expression was observed even on day 1 and persisted for 2-5 weeks, and exclusive in the gene gun bombarded area. ${ }^{10}$ With a regard to in vivo electroporation, we investigated the feasibility of HGF gene transfer via the portal vein in dimethylnitrosamine (DMN)-induced rat liver fibrosis. HGF gene transfer attenuated the fibrotic change and prolonged the survival of DMN rats, and also reduced the apoptotic cell death. ${ }^{13}$ However, these nonviral gene transfer methods also induced infiltration of inflammatory cells and mechanical damage in the site of gene transfer. On the other hand, in vivo lung-targeting gene therapy has been challenging due to the physical extracellular barriers, such as mucus, mucociliary clearance and glycocalyx proteins, and the innate or adaptive immunological systems. ${ }^{7}$ Preclinical and clinical studies of gene therapy for cystic fibrosis suggested that current levels of gene expression were too low to achieve clinical benefit. Repetitive administrations of viral vectors were also limited by the formation of neutralizing antibodies. In addition, almost all previous studies including the lung-directed one used the diseased organ as a target site to induce efficient transgene expression locally. However, we should avoid putting the diseased organ at risk as the targets of gene transfer. Therefore, in this study, we selected the skeletal muscle as a gene transfer site using nonviral in vivo electroporation system to avoid these problems in lung gene therapy.

In vivo electroporation-mediated gene transfer achieved rapid and persistent gene expression in the skeletal muscle in this study. GFP expression was detected on the day after gene transfer and persisted for 28 days. GFP expression was exclusively restricted to the quadriceps muscle. These data were identical to the previous reports of in vivo electroporation. ${ }^{39,40}$ On the other hand, in addition to the electroporation-related tissue damage described above, another problem of nonviral gene transfer is lower transfection efficiency compared with viral vector. Although human $\mathrm{HGF}$ in the 
quadriceps muscle and the lung were also detected at day 1 and peaked at days 3 and 5, respectively, human HGF concentration in the lung was significantly lower compared with that in the skeletal muscle. However, its level would be efficient to demonstrate the physiological effects according to the previous reports on HGF gene therapy. ${ }^{13,41}$ As a result of our observations, skeletal muscle-targeting in vivo-electroporation could be performed with the advantages of simplicity, safety, and without toxicity to the diseased organ.

Suppressions of fibrinogenesis and apoptosis are principal points in the therapy of lung fibrosis as described above. Our results of hydroxyproline assay and histological evaluation indicated the certain effects of HGF gene transfer on suppression of fibrinogenesis in the bleomycin-injected lung. Furthermore, HGF gene transfer also reduced the apoptosis of the bleomycin-injected lung significantly. Concerning the survival analysis of bleomycin-injected mice, Hattori et $a l^{42}$ reported the significant improvement of the survival rate of the mice deleted for the plasminogen activator inhibitor-1 (PAI-1) gene compared with that of wild-type mice. They suggested that the protective effect of PAI deletion could be attributed to the accelerated clearance of fibrin matrices. Their result emphasized the importance of fibrinogenesis suppression. In our study, the survival ratio of the bleomycininjected mice was significantly improved in HGFtransferred mice compared with GFP mice.

With regard to the limitations of this study, concentration of human HGF in the muscle and the lung decreased to around undetectable level of ELISA system at 28 days after gene transfer. However, clinical efficiency of our gene therapy protocol could be suggested by the following point. First, the expression of GFP in skeletal muscle was confirmed in five of six mice at day 28 in our study. And in previous reports regarding the skeletal muscle-targeting electroporation, gene expression was confirmed even in 15 weeks after gene transfer. ${ }^{43}$ Second, the physiological effect of HGF would be expectable even when its concentration decreased to undetectable level as reported previously. ${ }^{41}$ Third, skeletal muscle-targeting electroporation-mediated gene transfer could be repeated without apparent immune responses. ${ }^{44}$

Another problem of this study is electroporationrelated skeletal muscle damage. However, electroporation induced minimal damage of the skeletal muscle and mild degree of influx of inflammatory cells. And no dysfunction of the lower limb was observed in either group. These changes induced by electroporation were recovered within about 2 weeks in our preliminary study.

In conclusion, we developed a nonviral HGF gene therapy of bleomycin-induced lung fibrosis with a single skeletal muscle-targeting in vivo electroporation for the first time. This procedure could be applied as a practical gene therapy protocol of various diseased organs.

\section{Acknowledgements}

We thank Dr Emi Yokoyama for editing the manuscript. This work was supported in part by Grant-inAid for Scientific Research (No. 14770677 to YU) from Ministry of Education, Culture, Sports, Science and Technology of Japan.

\section{References}

1 Green FH. Overview of pulmonary fibrosis. Chest 2002;122:334S-339S.

2 Harrison Jr JH, Hoyt DG, Lazo JS. Acute pulmonary toxicity of bleomycin: DNA scission and matrix protein mRNA levels in bleomycin-sensitive and -resistant strains of mice. Mol Pharmacol 1989;36: 231-238.

3 Schrier DJ, Phan SH, McGarry BM. The effects of the nude (nu/nu) mutation on bleomycin-induced pulmonary fibrosis. Am Rev Respir Dis 1983;127:614-617.

4 Mason RJ, Leslie CC, McCormick-Shannon K, et al. Hepatocyte growth factor is a growth factor for rat alveolar type II cells. Am J Respir Cell Mol Biol 1994;11:561-567.

5 Shiratori M, Michalopoulos G, Shinozuka H, et al. Hepatocyte growth factor stimulates DNA synthesis in alveolar epithelial type II cells in vitro. Am J Respir Cell Mol Biol 1995;12:171-180.

6 Yaekashiwa M, Nakayama S, Ohnuma K, et al. Simultaneous or delayed administration of hepatocyte growth factor equally represses the fibrotic changes in murine lung injury induced by bleomycin. Am J Respir Crit Care Med 1997;156:1937-1944.

7 Ferrari S, Griesenbach U, Geddes DM, et al. Immunological hurdles to lung gene therapy. Clin Exp Immunol 2003;132:1-8.

8 Wang H, Reaves PY, Gardon ML, et al. Angiotensin Iconverting enzyme antisense gene therapy causes permanent antihypertensive effects in the SHR. Hypertension 2000;35:202-208.

9 Marshall E. Gene therapy death prompts review of adenovirus vector. Science 1999;286:2244-2245.

10 Umeda Y, Hirose H, Yoshikawa S, et al. Nonviral gene gun-mediated CTLA4-Ig gene transfer for modification of donor organs. Transplant Proc 2001;33:243-245.

11 Umeda Y, Iwata H, Yoshikawa S, et al. Gene gunmediated CTLA4Ig-gene transfer for modification of allogeneic cardiac grafts. Transplant Proc 2002;34:2622-2623.

12 Matsuno Y, Iwata H, Yoshikawa S, et al. Suppression of graft coronary arteriosclerosis by gene gun-mediated CTLA4-lg gene transfer. Transplant Proc 2002;34: 2619-2621.

13 Matsuno $\mathrm{Y}$, Iwata $\mathrm{H}$, Umeda $\mathrm{Y}$, et al. Hepatocyte growth factor gene transfer into the liver via the portal vein using electroporation attenuates the rat liver cirrhosis. Gene Therapy 2003;10:1559-1566.

14 Nakamura T, Nishizawa T, Hagiya M, et al. Molecular cloning and expression of human hepatocyte growth factor. Nature 1989;342:440-443. 
15 Niwa H, Yamamura K, Miyazaki J. Efficient selection for high-expression transfectants with a novel eukaryotic vector. Gene 1991;108:193-199.

16 Ashcroft T, Simpson JM, Timbrell V. Simple method of estimating severity of pulmonary fibrosis on a numerical scale. J Clin Pathol 1988;41:467-470.

17 Nakamura T, Nawa K, Ichihara A. Partial purification and characterization of hepatocyte growth factor from serum of hepatectomized rats. Biochem Biophys Res Commun 1984;122:1450-1459.

18 Weidner KM, Arakaki N, Hartmann G, et al. Evidence for the identity of human scatter factor and human hepatocyte growth factor. Proc Natl Acad Sci USA 1991;88:7001-7005.

19 Montesano R, Matsumoto $\mathrm{K}$, Nakamura $\mathrm{T}$, et al. Identification of a fibroblast-derived epithelial morphogen as hepatocyte growth factor. Cell 1991;67: 901-908.

20 Schmidt C, Bladt F, Goedecke S, et al. Scatter factor/ hepatocyte growth factor is essential for liver development. Nature 1995;373:699-702.

21 Dohi M, Takashi H, Yamamoto K, et al. Hepatocyte growth factor attenuates collagen accumulation in a murine model of pulmonary fibrosis. Am J Respir Crit Care Med 2000;162:2302-2307.

22 Pepper MS, Matsumoto K, Nakamura T, et al. Hepatocyte growth factor increases urokinase-type plasminogen activator (u-PA) and $\mathrm{u}-\mathrm{PA}$ receptor expression in Madin-Darby canine kidney epithelial cells. J Biol Chem 1992;267:20493-20496.

23 Matsuda Y, Matsumoto K, Ichida T, et al. Hepatocyte growth factor suppresses the onset of liver cirrhosis and abrogates lethal hepatic dysfunction in rats. J Biochem 1995;118:643-649.

24 Kuenzler KA, Pearson PY, Schwartz MZ. Hepatoctye growth factor pretreatment reduces apoptosis and mucosal damage after intestinal ischemia-reperfusion. J Pediatr Surg 2002;37:1093-1097.

25 Nakamura T, Mizuno S, Matsumoto K, et al. Myocardial protection from ischemia/reperfusion injury by endogenous and exogenous HGF. J Clin Invest 2000;106:1511-1519.

26 Nagano T, Mori-Kudo I, Tsuchida A, et al. Ameliorative effect of hepatocyte growth factor on glycerolinduced acute renal failure with acute tubular necrosis. Nephron 2002;91:730-738.

27 Kuwano K, Hagimoto N, Kawasaki M, et al. Essential roles of the Fas-Fas ligand pathway in the development of pulmonary fibrosis. J Clin Invest 1999;104:13-19.

28 Kuwano K, Miyazaki $\mathrm{H}$, Hagimoto $\mathrm{N}$, et al. The involvement of Fas-Fas ligand pathway in fibrosing lung diseases. Am J Respir Cell Mol Biol 1999;20: 53-60.

29 Matute-Bello G, Liles WC, Steinberg KP, et al. Soluble Fas ligand induces epithelial cell apoptosis in humans with acute lung injury (ARDS). J Immunol 1999; 163:2217-2225.

30 Kitamura Y, Hashimoto S, Mizuta N, et al. Fas/FasLdependent apoptosis of alveolar cells after lipopoly- saccharide-induced lung injury in mice. Am J Respir Crit Care Med 2001;163:762-769.

31 Vernooy JH, Dentener MA, van Suylen RJ, et al. Intratracheal instillation of lipopolysaccharide in mice induces apoptosis in bronchial epithelial cells: no role for tumor necrosis factor-alpha and infiltrating neutrophils. Am J Respir Cell Mol Biol 2001;24: 569-576.

32 Otterbein LE, Chin BY, Mantell LL, et al. Pulmonary apoptosis in aged and oxygen-tolerant rats exposed to hyperoxia. Am J Physiol Lung Cell Mol Physiol 1998;275:L14-L20.

33 Howlett CE, Hutchison JS, Veinot JP, et al. Inhaled nitric oxide protects against hyperoxia-induced apoptosis in rat lungs. Am J Physiol Lung Cell Mol Physiol 1999;277:L596-L605.

34 Aljandali A, Pollack H, Yeldandi A, et al. Asbestos causes apoptosis in alveolar epithelial cells: role of iron-induced free radicals. J Lab Clin Med 2002;137:330-339.

35 Stammberger U, Gaspert A, Hillinger S, et al. Apoptosis induced by ischemia and reperfusion in experimental lung transplantation. Ann Thorac Surg 2000;69:1532-1536.

36 Maeyama T, Kuwano K, Kawasaki M, et al. Attenuation of bleomycin-induced pneumopathy in mice by monoclonal antibody to interleukin-12. Am J Physiol Lung Cell Mol Physiol 2001;280:L1128-L1137.

37 Sharma SK, MacLean JA, Pinto C, et al. The effect of an anti-CD3 monoclonal antibody on bleomycin-induced lymphokine production and lung injury. Am J Respir Crit Care Med 1996;154:193-200.

38 Idell S, Gonzalez KK, MacArthur CK, et al. Bronchoalveolar lavage procoagulant activity in bleomycininduced lung injury in marmosets. Characterization and relationship to fibrin deposition and fibrosis. Am Rev Respir Dis 1987;136:124-133.

39 Aihara H, Miyazaki J. Gene transfer into muscle by electroporation in vivo. Nat Biotechnol 1998;16: 867-870.

40 Xue F, Takahara T, Yata Y, et al. Attenuated acute liver injury in mice by naked hepatocyte growth factor gene transfer into skeletal muscle with electroporation. Gut 2002;50:558-562.

41 Ueki T, Kaneda Y, Tsutsui H, et al. Hepatocyte growth factor gene therapy of liver cirrhosis in rats. Nat Med 1999;5:226-230.

42 Hattori N, Degen JL, Sisson TH, et al. Bleomycininduced pulmonary fibrosis in fibrinogen-null mice. J Clin Invest 2000;106:1341-1350.

43 Maruyama H, Ataka K, Gejyo F, et al. Long-term production of erythropoietin after electroporationmediated transfer of plasmid DNA into the muscles of normal and uremic rats. Gene Therapy 2001;8: 461-468.

44 Tanaka T, Ichimaru N, Takahara S, et al. In vivo gene transfer of hepatocyte growth factor to skeletal muscle prevents changes in rat kidneys after 5/6 nephrectomy. Am J Transplant 2002;2:828-836. 